See discussions, stats, and author profiles for this publication at:

https://www.researchgate.net/publication/232504329

\title{
Morphology and Behavior: Phrenology Revisited
}

Article in Review of General Psychology · September 2008

DOI: $10.1037 / 1089-2680.12 .3 .297$

CITATIONS

11

3 authors, including:

\section{Michael Frederick}

University of Baltimore

5 PUBLICATIONS 20 CITATIONS

SEE PROFILE

\section{READS}

199
R. Nathan Pipitone

Florida Gulf Coast University

15 PUBLICATIONS 552 CITATIONS

SEE PROFILE

All content following this page was uploaded by R. Nathan Pipitone on 26 June 2014. 


\title{
Morphology and Behavior: Phrenology Revisited
}

\author{
Gordon G. Gallup, Jr., Michael J. Frederick, and R. Nathan Pipitone \\ University at Albany, State University of New York
}

\begin{abstract}
Research conducted by evolutionary psychologists and biologists shows that subtle individual differences in body morphology can be related to surprising and important differences in human behavior and reproductive success. The authors summarize recent work on these effects as they relate to fluctuating asymmetry, facial attractiveness, finger digit morphology, sexually dimorphic differences in body configuration, and head circumference. Examples include the discovery that women who have sex with bilaterally symmetrical men report more orgasms; men with attractive faces have higher quality sperm; the length of the index finger in relation to the ring finger is related to verbal fluency, spatial ability, and the risk of autism; women with an hourglass figure have more regular menstrual cycles and are more fertile; and the sound of a person's voice predicts his or her sexual behavior.
\end{abstract}

Keywords: fluctuating asymmetry, facial attractiveness, body configuration, reproductive competition, evolution and behavior

The history of psychology is punctuated by attempts to relate different features of the body to behavior. Phrenology was a classic instance of this trend, in which subtle variations in the configuration of the cranium were taken as evidence for underlying differences in personality (see Boring, 1950, for a historical critique). Other examples include attempts to relate differences in body configuration and physique to personality traits (e.g., Sheldon, 1954). For want of supporting evidence, however, this trend largely disappeared. Though phrenology as a science was discredited, in one sense it was a starting point for trying to examine the relationship between body morphology and behavior.

Phrenologists overemphasized the predictive value of physical characteristics, attempting to define an individual's whole personality on the basis of cranial features. Behaviorism, which stresses the role of learning and experience, was in part a reaction to the biological determinism

Gordon G. Gallup, Jr., Michael J. Frederick, and R. Nathan Pipitone, University at Albany, State University of New York.

We thank Steven Platek, Greg Ross, Yu-Ming Mo, and Susan Hughes for helpful comments on earlier drafts of this article.

Correspondence concerning this article should be addressed to Gordon G. Gallup, Jr., Department of Psychology, State University of New York at Albany, Albany, NY 12222. E-mail: gallup@albany.edu of phrenology. It would be a mistake, however, to ignore the fact that we are all biological creatures with brains and bodies that have been shaped by evolution. There is now new emerging evidence for interesting links between our morphology and behavior. An individual's physical characteristics may relate to behavior in two ways. First, the characteristics may reveal some underlying process (e.g., hormonal profile) that has broad effects on the body and the brain. Second, these physical features may influence how other people respond to and interact with that person. This can occur in subtle ways that people may not be aware of.

Here we summarize new evidence gathered by researchers interested in the impact of evolution on behavior, which shows that subtle variation in a variety of morphological features can be related to substantial and important differences in human behavior. This is not an exhaustive review. Rather it is a selection of topics and research that can be used as an overview for those unfamiliar with the impact of evolution on human behavior.

\section{Fluctuating Asymmetry}

Perfect bilateral symmetry obtains when the morphological features on one side of the body represent an exact mirror image of those on the opposing side. All people show small random 
deviations from bilateral symmetry, referred to as fluctuating asymmetry (FA); for example, the length of some of the fingers on one hand may be slightly different from those on the other. These asymmetries are thought to be a consequence of an inability by the fetus to buffer against stressors and disturbances that occur during embryological development (Ludwig, 1932).

FA rarely results in organisms being grossly out of proportion. It is usually subtle and not obvious until careful measurements are taken with a pair of calipers. Often the deviations are on the order of $1-2 \%$ of the size of the trait being measured, but exposure to high stress levels can sometime raise this to 3-5\% (Parsons, 1990). The developmental instability that gives rise to FA can lead to the accumulation of slight imperfections that reduce overall health and fecundity. Growing evidence shows that as the magnitude of FA increases, there is a corresponding decrease in a variety of measures of fitness, as is defined by an organism's genetic representation in subsequent generations. Elevated FA among adults is related to increased vulnerability to disease and higher levels of morbidity (Livshits \& Kobyliansky, 1991), whereas low FA is associated with increased genetic, physical, and mental health (Thornhill \& Moller, 1997). FA can vary across individuals, populations, and species. Evidence derived from fossilized teeth suggests that over the past several million years the magnitude of FA among humans has increased in relation to that of other primates (Frederick \& Gallup, 2007).

There is substantial evidence that FA has behavioral implications as well. Men and women with low FA are not only more fertile, they are also judged as being more attractive than those with high FA (Thornhill \& Gangestad, 1994). Low-FA men have more sexual partners, they are more athletic, and they are more likely to commit sexual infidelity (Gangestad \& Thornill, 1997). Men with low FA also have a lower resting metabolic rate (Manning, Koukourakis, \& Brodie, 1997), and they are independently judged as being better dancers (W. M.Brown et al., 2005). Women in sexual relationships with low-FA men experience more frequent orgasms than those with high-FA partners (Thornhill, Gangestad, \& Comer, 1995). There is also evidence that the risk of developing attention deficit/hyperactivity disorder type behaviors is proportional to the magnitude of FA (Burton et al., 2003; Stevenson et al., 2006). Even intelligence appears to be related to variation in FA. Low-FA men score significantly higher on standardized intelligence tests than do their high-FA counterparts (Furlow, Armijo-Prewitt, Gangestad, \& Thornhill, 1997; Thoma et al., 2006).

Because FA is inversely proportional to such a broad array of fitness indicators, it is not surprising that natural selection has operated to put a premium on differences in other more easily discernable traits that signal low FA. As a case in point, Thornhill and Gangestad (1999b) had male college students agree to wear freshly laundered t-shirts to bed and return the shirts to the laboratory the next day. The shirts were placed in coded plastic bags, and each of the donors was measured for slight deviations from bilateral symmetry across a number of physical traits. Women who did not know the source of the shirts were asked to smell the shirts and rate the extent to which they found the different t-shirt odors to be attractive. Most women failed to reliably distinguish between the different shirts, but those who were in the ovulatory phase of their menstrual cycle rated shirts worn by low-FA men as smelling more attractive than those worn by high-FA men.

Mate choice is an important dimension of fitness. Women have a strong vested interest in ensuring that their infants inherit the best genes possible. Offspring fathered by high-quality men have a better chance of showing traits that will bode well for their own reproductive success, which in turn serve to perpetuate their mother's genes. Thornhill and Gangestad's (1999b) results are consistent with the idea that menstrual cycle variation in male body odor preferences was favored among women during human evolutionary history to increase the likelihood of conception as a consequence of sexual encounters with genetically high-quality men.

As evidence for another FA signal in a different domain, Hughes, Harrison, and Gallup (2002) measured deviations from bilateral symmetry in college students and had them count from 1 to 10 while their voices were being recorded. These recordings were then rated for attractiveness by students who did not know and had not seen the people whose voices had been recorded. Hughes et al. discovered that the voices of both men and women with low FA 
were rated as being more attractive than those with high FA. It appears that not only does body odor contain information related to fitness, but also that the same is true for subtle differences in the mere sound of a person's voice. People with attractive voices not only show fewer deviations from bilateral symmetry, they tend to have more sex-typical body configurations; that is, men with attractive voices have broad shoulders and narrow hips, whereas women with attractive voices have more accentuated hourglass figures (Hughes, Dispenza, \& Gallup, 2004). People with attractive voices also begin having sex at an earlier age and have more sex partners (Hughes et al., 2004). Recent research based on a longitudinal study of voice samples taken from women at different times during their menstrual cycle reveals a significant increase in attractiveness ratings for voices collected during the ovulatory phase, when the likelihood of conception is highest (Pipitone \& Gallup, in press). People appear to have been selected during evolutionary history to prefer a variety of features or cues in mating partners that predict reproductive viability and resistance to developmental insults, which are indicated by low levels of FA.

\section{Facial Attractiveness}

Faces are important. We not only recognize people on the basis of their facial features, but faces also play a role in interpersonal attraction. A common stereotype is that facial attractiveness is a social construction, driven by learned, arbitrary, sociocultural influences. However, data have begun to emerge that challenge this position (for a review, see Thornhill \& Gangestad, 1999a). Not only is there relatively good consensus among people as to which faces are attractive, but attractive faces appear to be a cross-cultural universal (Cunningham, Roberts, Barbee, Druen, \& Wu, 1995). Faces that Asians find attractive among each other are also rated as attractive by Caucasians, and vice versa. Ratings of facial attractiveness tend to be consistent across ethnic groups, sex, sexual orientation, and age. Coupled with the fact that even neonates spend significantly more time looking at faces that adults find attractive (Rubenstein, Langlois, \& Kalakanis, 1999), these data strongly suggest that the perception of facial attractiveness may have a biological component.

Consistent with predictions derived from evolutionary theory, there is growing evidence that individual differences in facial attractiveness signal important underlying biological properties. People with attractive faces are healthier (Shackelford \& Larsen, 1999) and tend to be more symmetrical (Grammer \& Thornhill, 1994). Humans were selected during evolutionary history to find certain faces attractive because, just as with voices, they were associated with features that predict fitness. In other words, there may have been adaptive benefits to mating with people on the basis of the appearance of their faces.

Several recent findings provide strong support for this position. In one study, Soler et al. (2003) took facial photographs and collected semen samples from male college students. A composite semen quality score for each man was derived by measuring sperm count, sperm motility, and sperm morphology. Next, a large sample of women were asked to rate the photos of these men for attractiveness. The researchers discovered that ratings of facial attractiveness were significantly correlated with the independent semen assay results. Men with faces that women found attractive tended to have more fertile, higher-quality semen.

In another study, Henderson and Anglin (2003) took a sample of facial photographs, consisting of an equal proportion of men and women, from old high school yearbooks. Using a public database that included the date of birth and death for the people in the yearbooks, Henderson and Anglin calculated longevity data to the nearest month. Male and female college students were instructed to rate each of these yearbook photos for attractiveness and health. Ratings of facial attractiveness were correlated with ratings of health. More important, attractiveness ratings of the high school photos were correlated with longevity. Both men and women with attractive faces tended to live significantly longer.

As further evidence that faces are important, it has been shown that facial attractiveness among women is positively correlated with their estrogen levels, which are related to individual differences in fertility (Law Smith et al., 2006). Likewise, men who are heterozygotic at the Major Histocompatibility Complex (MHC) 
loci are judged by women as being more attractive (Roberts et al., 2005). MHC genes code for proteins involved in the body's immunological response to pathogens, and therefore being more heterozygous means being more disease resistant and better able to protect against infectious diseases (J. L.Brown, 1997). Ratings of facial attractiveness also covary with measures of facial symmetry. People with attractive faces tend to be more symmetrical (e.g., Fink, Neave, Manning, \& Grammer, 2006), and as noted, bilateral symmetry is a ubiquitous index of fitness. Not surprisingly, facial attractiveness in both men and women predicts number of sex partners (Rhodes, Simmons, \& Peters, 2005).

All of this supports the "what is beautiful is good" phenomenon (Dion, Berscheid, \& Walster, 1972; Langlois et al., 2000) as it relates to the reproductive benefits of facial attractiveness. Rather than being an artifact of sociocultural influences, what turns out to be attractive is a reflection of how natural selection has shaped the human nervous system to process facial information as a consequence of how it relates to differential reproduction and fitness.

\section{Finger Digit Ratios}

As strange as it may seem, your hands say something about what happened to you during embryological development. Exposure to different levels of sex hormones in utero leaves telltale effects on your fingers. People exposed to elevated levels of testosterone tend to have ring fingers (the fourth digit: 4D) that exceed the length of their index finger (the second digit: 2D). Estrogen exposure has the opposite effect; the index finger tends to be longer than the ring finger. These differences can be represented quantitatively by $2 \mathrm{D}: 4 \mathrm{D}$ ratios, in which a ratio of less than 1.0 is evidence for high testosterone, and a ratio that exceeds 1.0 is evidence for exposure to elevated levels of estrogen during prenatal development.

Men tend to have a 2D:4D ratio of less than 1.0 , while in women the ratio is usually close to or greater than 1.0. This sex difference has been recorded by anatomists and anthropologists for over a century (Baker, 1888; Phelps, 1952). There are also connections to be found in history, folklore, and palmistry between the length of the ring finger and musical or creative abilities (see Sorell, 1968). Casanova actually boasted to a friend about the length of his ring finger in relation to his index finger (Casanova, 1997).

Evidence suggests that 2D:4D ratio is heritable (Manning, Trivers, Thornhill, \& Singh, 2000) and is established by about the 13th or 14th week of pregnancy (Garn, Burdi, Babler, \& Stinson, 1975; Manning, Scutt, Wilson, \& Lewis-Jones, 1998). While variation in finger morphology might seem trivial, it is now known that there are benefits associated with having a high ratio for women and a low ratio for men. Men with a low 2D:4D ratio have higher serum testosterone levels and higher sperm counts (Manning et al., 1998). They are also judged as being more attractive by women after a brief social interaction (Roney \& Maestripieri, 2004). Women with a high 2D:4D ratio have higher levels of self-reported physical attractiveness (Wade, Shanley, \& Imm, 2004) and selfreported assertiveness (Wilson, 1983). In terms of reproductive success, men with a low 2D:4D ratio have more children, while for women, a high 2D:4D ratio is associated with having more children (Manning, Barley, et al., 2000). Couples for whom there was a large difference between the female's ratio and the male's ratio (high female 2D:4D-low male 2D:4D) produced the most offspring, and these differences were independent of age.

Because the 2D:4D ratio is related to sex differences in exposure to prenatal sex hormones, it may imply something about the degree of masculinization versus feminization of the brain. For example, there are many more left-handed men than women, and Manning, Trivers, et al. (2000) found that left-hander people had lower, more masculine digit ratios. Likewise, men have a higher risk of developing autism, and children with autism have a lower than average 2D:4D ratio (Manning, BaronCohen, Wheelwright, \& Sanders, 2001). Women tend to outperform men on tasks that involve verbal fluency (Halpern, 1992; McGlone, 1986), and Manning (2002) reported a positive relationship between verbal fluency and higher, more feminine digit ratios in both men and women. The reverse is true for visual spatial ability. Men tend to outperform women on visual tasks such as the mental rotation task (Masters, 1998), and a lower 2D:4D ratio is associated with improved spatial performance (Collaer, Reimers, \& Manning, 2007; Manning 
\& Taylor, 2001). Among professional musicians, men outnumber women, and Sluming and Manning (2000) found that a low 2D:4D ratio predicted high musical ability.

Low 2D:4D ratios also correlate with athletic ability (Manning \& Taylor, 2001). In men and women, a low 2D:4D ratio predicts better performance on endurance running (Manning, Morris, \& Caswell, 2007). Low 2D:4D men score higher on scales of physical aggression (Bailey \& Hurd, 2005), and low 2D:4D women show higher levels of reactive aggression (Benderlioglu \& Nelson, 2004). In a simulated war game environment, a low 2D:4D ratio predicted increased aggression in both sexes (McIntyre et al., 2007). Women with a low 2D:4D ratio also have voices that are rated as more dominant (Hughes, Pastizzo, \& Gallup, 2008). There is even evidence that finger digit ratios may be related to sexual orientation, particularly among women with a low 2D:4D ratio (Kraemer et al., 2006; Williams et al., 2000).

There can be pros and cons to having a high or low digit ratio regardless of gender. A high 2D:4D ratio is correlated with improved verbal fluency, while a low 2D:4D ratio is correlated with improved spatial, musical, and athletic abilities. In men, a low 2D:4D ratio is linked to an increased risk of autism (Manning et al., 2001), but high 2D:4D men had myocardial infarctions at an earlier age (Manning \& Bundred, 2001). In women, a low 2D:4D ratio is associated with a reduction in fertility (Manning, Barley, et al., 2000), while a high 2D:4D ratio correlates with an increased risk of breast cancer (Manning \& Leinster, 2001).

\section{Body Configuration}

In the song Big Bad John, written by Jimmy Dean and Roy Acuff (copyright, 1961), there is a phrase "kinda broad at the shoulder and narrow at the hip." Adult humans tend to show reliable sexually dimorphic body configuration differences. Women often have a proverbial hourglass figure, consisting of a narrow waist and broad hips, while men tend to be more wedge-shaped, with broad shoulders and narrow hips. These differences can be represented quantitatively by computing waist-to-hip ratios (WHRs) and shoulder-to-hip ratios (SHRs), by using an anthropometric measuring tape to contrast the width or circumference of one of these features to the other.
Women with narrow waists and broad hips are rated as being more attractive, with the most attractive WHR being about 7 (Singh, 1993). In women, the configuration of the waist in relation to the hips has a substantial heritability component (Nelson, Vogler, Pedersen, \& Miles, 1999). Consistent with an evolutionary analysis of interpersonal attraction, WHRs are correlated with a number of reproductive parameters. Women with low WHRs ovulate more frequently (Jasienska, Ziomkiewicz, Ellison, Lipson, \& Thune, 2004) and have fewer irregular menstrual cycles (Van Hoof et al., 2000). Low WHR increases the likelihood of pregnancy in women undergoing artificial insemination (Zaadstra et al., 1993) and in vitro fertilization (Waas, Waldenstrom, Rossner, \& Hellberg, 1997).

A narrow waist and broad hips signal that a woman is not pregnant and her pelvic morphology is likely to provide for unencumbered childbirth (Hughes \& Gallup, 2003). Women with low WHRs begin having sex at an earlier age, have more sex partners, and are more prone to infidelity (Hughes et al., 2004). Low WHRs also tend to be associated with a lower risk of heart disease, stroke, diabetes, gall bladder disease, kidney disease, and various cancers (see reviews by Singh, 1993, and Singh \& Singh, 2006).

Men with broad shoulders and narrow hips (high shoulder-to-hip ratios) have higher testosterone levels and are rated as being more attractive. Hughes et al. (2004) found that men with high SHRs had sex an earlier age, had more sex partners, and were more likely to be unfaithful. Indeed, Hughes et al. found that variation in SHR accounted for over $25 \%$ of the variance in promiscuity in a sample of college men. As evidence that SHR signals physical prowess, men with high SHRs also have higher grip strength scores, and they tend to have been more aggressive in high school (Gallup, White, \& Gallup, 2007).

\section{Brain Size and Intelligence}

While bumps on your head do not make a difference, the size of your head does. There is a growing and impressive amount of evidence for a substantial relationship between brain size and intelligence (see Ash \& Gallup, 2007). Head circumference is a proxy (albeit imper- 
fect) for brain size, and correlations of about 0.2 between head circumference and scores on standardized IQ tests are well established (e.g., Vernon, Wickett, Bazana, \& Stelmack, 2000).A large number of recent studies havefound correlations of 0.4 to 0.5 between individual differences in brain volume and performance on IQ tests, by using magnetic resonance imaging as a more precise means of estimating brain size (see Wickett, Vernon, \& Lee, 2000).

\section{Concluding Remarks}

There is more and more evidence that subtle and what might otherwise appear to be inconsequential individual differences in body morphology can actually account for a significant proportion of the variance in important aspects of human behavior. Although early attempts by phrenologists to use variation in cranial morphology to infer different aspects of personality were misguided, there is now evidence that variation in other physical features can be used to predict behavior. This review covers a representative, but by no means exhaustive, account of recent studies that implicate a connection between body morphology and behavior.

Taken together, these findings suggest that behavior is first and foremost a biological phenomenon. Genetic and hormonal factors that shape individual differences in human development, body morphology, and appearance have important behavioral effects. Results such as these are consistent with the idea that the evolutionary pressures that shaped human biology also exerted parallel influences on many aspects of human behavior.

\section{References}

Ash, J., \& Gallup, G. G., Jr. (2007). Brain size, intelligence, and paleoclimatic variation. In G. Geher \& G. Miller (Eds.), Mating intelligence (pp. 313-335). New York: Erlbaum.

Bailey, A. A., \& Hurd, P. L. (2005). Finger length ratio (2D:4D) correlates with physical aggression in men but not in women. Biological Psychology, 68, 215-222.

Baker, F. (1888). Anthropological notes on the human hand. American Anthropologist, 1, 51-76.

Benderlioglu, Z., \& Nelson, R. J. (2004). Digit length ratios predict reactive aggression in women, but not in men. Hormones \& Behavior, 46, 558-564.
Boring, E. G. (1950). A history of experimental psychology. New York: Appleton-Century-Crofts.

Brown, J. L. (1997). A theory of mate choice based on heterozygosity. Behavioral Ecology, 8, 60-65.

Brown, W. M., Cronk, L. Grochow, K., Jacobson, A., Liu, C. K., Popovic, Z., \& Trivers, R. (2005). Dance reveals symmetry especially in young men. Nature, 438, 1148-1150.

Burton, C., Stevenson, J. C., Williams, D. C., Everson, P. M., Mahoney, E. R., \& Trimble, J. E. (2003). Attention-Deficit Hyperactivity Disorder (AD/HD) and Fluctuating Asymmetry (FA) in a college sample: An exploratory study. American Journal of Human Biology, 15, 601-619.

Casanova, G. (1997). The history of my life (W. R. Trask, Trans.). Baltimore: John Hopkins University Press.

Collaer, M. L., Reimers, S., \& Manning, J. T. (2007). Visuospatial performance on an internet line judgment task and potential hormonal markers: Sex, sexual orientation, and 2D:4D. Archives of Sexual Behavior, 36, 177-192.

Cunningham, M. R., Roberts, A. R., Barbee, A. P., Druen, P. B., \& Wu, C.-H. (1995). Their ideas of beauty are, on the whole, the same as ours: Consistency and variability in the cross-cultural perception of female physical attractiveness. Journal of Personality and Social Psychology, 68, 261-279.

Dion, K., Berscheid, E., \& Walster, E. (1972). What is beautiful is good. Journal of Personality and Social Psychology, 24, 285-290.

Fink, B., Neave, N., Manning, J. T., \& Grammer, K. (2006). Facial symmetry and judgments of attractiveness, health and personality. Personality and Individual Differences, 41, 491-499.

Frederick, M. J., \& Gallup, G. G., Jr. (2007). Fluctuating dental asymmetry in great apes, fossil hominins, and modern humans: Implications for changing stressors during human evolution. Acta Psychologica Sinica, 39, 489-494.

Furlow, F. B., Armijo-Prewitt, T., Gangestad, S. W., \& Thornhill, R. (1997). Fluctuating asymmetry and psychometric intelligence. Proceedings of the Royal Society: Biological Sciences, 264, 823-829.

Gallup, A. C., White, D. D., \& Gallup, G. G., Jr. (2007). Handgrip strength predicts body morphology, aggression, and sexual behavior in males. Evolution and Human Behavior, 28, 423-429.

Gangestad, S. W., \& Thornhill, R. (1997). The evolutionary psychology of extrapair sex: The role of fluctuating asymmetry. Evolution and Human Behavior, 18, 69-88.

Garn, S. M., Burdi, A. R., Babler, W. J., \& Stinson, S. (1975). Early prenatal attainment of adult metacarpal-phalangeal rankings and proportions. American Journal of Physical Anthropology, 43, 327-332.

Grammer, K., \& Thornhill, R. (1994). Human (Homo sapiens) facial attractiveness and sexual selection: 
The role of symmetry and averageness. Journal of Comparative Psychology, 108, 233-242.

Halpern, D. F. (1992). Sex differences in cognitive abilities. London: Erlbaum.

Henderson, J. A., \& Anglin, J. M. (2003). Facial attractiveness predicts longevity. Evolution and Human Behavior, 24, 351-356.

Hughes, S., Dispenza, F., \&. Gallup, G. G., Jr. (2004). Ratings of voice attractiveness predict sexual behavior and body configuration. Evolution and Human Behavior, 25, 295-304.

Hughes, S., \& Gallup, G. G., Jr. (2003). Sex differences in morphological predictors of sexual behavior: Shoulder to hip and waist to hip ratios. Evolution and Human Behavior, 24, 173-178.

Hughes, S., Harrison, M., \& Gallup, G. G., Jr. (2002). The sound of symmetry: Voice as a marker of developmental instability. Evolution and Human Behavior, 23, 173-180.

Hughes, S., Pastizzo, M. J., \& Gallup, G. G., Jr. (2008). The sound of symmetry revisited: Subjective and objective analyses of voice. Journal of Nonverbal Behavior, 32, 93-108.

Jasienska, G., Ziomkiewicz, A., Ellison, P. T., Lipson, S. F., \& Thune, I. (2004). Large breasts and narrow waists indicate high reproductive potential. Proceedings of the Royal Society of London, Series B: Biological Sciences, 271, 1213-1217.

Jones, D. (1996). Physical attractiveness and the theory of sexual selection: Results from five populations. Ann Arbor: Museum of Anthropology, University of Michigan.

Kraemer, B., Noll, T., Delsignore, A., Milos, G., Schnyder, U., \& Hepp, U. (2006). Finger length ratio (2D:4D) and dimensions of sexual orientation. Neuropsychobiology, 53, 210-214.

Kretschmer, E. (1925). Physique and character. New York: Harcourt.

Langlois, J. H., Kalakanis, L., Rubenstein, A. J., Larson, A., Hallam, M., \& Smoot, M. (2000). Maxims or myths of beauty? A meta-analytic and theoretical review. Psychological Bulletin, 126, 390-423.

Law Smith, M. J., Perrett, D. I., Jones, B. C., Cornwell, R. E., Moore, F. R., Feinberg, D. R., et al.(2006). Facial appearance is a cue to oestrogen levels in women. Proceedings of the Royal Society $B, 273,135-140$.

Livshits, G., \& Kobyliansky, E. (1991). Fluctuating asymmetry as a possible measure of developmental homeostasis in humans: A review. Human Biology, 63, 441-466.

Ludwig, W. (1932). Das Rechts-Links Problem im Tierreich und beim Menschen. Berlin: Springer.

Manning, J. T. (2002). Digit ratio: A pointer to fertility, behavior and health. New Brunswick, NJ: Rutgers University Press.
Manning, J. T., Barley, L., Lewis-Jones, I., Walton, J., Trivers, R. L., Thornhill, R., et al. (2000). The $2^{\text {nd }}$ to $4^{\text {th }}$ digit ratio, sexual dimorphism, population differences and reproductive success: Evidence for early antagonistic genes. Evolution and Human Behavior, 21, 163-183.

Manning, J. T., Baron-Cohen, S., Wheelwright, S., \& Sanders, G. (2001). The $2^{\text {nd }}$ to $4^{\text {th }}$ digit ratio and autism. Developmental Medicine and Child Neurology, 43, 160-164.

Manning, J. T., \& Bundred, P. E. (2001). The ratio of second to fourth digit length and age at first myocardial infarction in men: A link with testosterone? British Journal of Cardiology, 8, 720-723.

Manning, J. T., Koukourakis, K., \& Brodie, D. A. (1997). Fluctuating asymmetry, metabolic rate and sexual selection in human males. Evolution and Human Behavior, 17, 15-21.

Manning, J. T., \& Leinster, S. (2001). The ratio of $2^{\text {nd }}$ to $4^{\text {th }}$ digit length and age at presentation of breast cancer: A link with prenatal oestrogen? The Breast, 22, 61-69.

Manning, J. T., Morris, L., \& Caswell, N. (2007). Endurance running and digit ratio (2D:4D): Implications for fetal testosterone effects on running speed and vascular health. American Journal of Human Biology, 19, 416-421.

Manning, J. T., Scutt, D., Wilson, J., \& Lewis-Jones, D. I. (1998). The ratio of 2 nd to 4 th digit length: A predictor of sperm numbers and concentrations of testosterone, luteinizing hormone and oestrogen. Human Reproduction, 13, 3000-3004.

Manning, J. T., \& Taylor, R. P. (2001). Second to fourth digit ratio and male ability in sport: Implications for sexual selection in humans. Evolution and Human Behavior, 22, 61-69.

Manning, J. T., Trivers, R. L., Thornhill, R., \& Singh, D. (2000). $2^{\text {nd }}$ to $4^{\text {th }}$ digit ratio and left lateralized preference in Jamaican children. Laterality, 5, 121-132.

Masters, M. S. (1998). The gender difference on the mental rotations test is not due to performance factors. Memory \& Cognition, 26, 444-449.

McGlone, J. (1986). The neuropsychology of sex differences in human brain organization. Advances in Clinical Neuropsychology, 3, 1-30.

McIntyre, M. H., Barrett, E. S., McDermott, R., Johnson, D. D. P., Cowden, J., \& Rosen, S. P. (2007). Finger length ratio (2D:4D) and sex differences in aggression during a simulated war game. Personality \& Individual Differences, 42, 755-764.

Nelson, T. L., Vogler, G. P., Pedersen, N. L., \& Miles, T. P. (1999). Genetic and environmental influences in waist-to-hip ratio and waist circumference in an older Swedish twin population. International Journal of Obesity, 23, 449-455. 
Parsons, P. A. (1990). Fluctuating asymmetry: An epigenetic measure of stress. Biological Reviews, 65, 131-145.

Phelps, V. R. (1952). Relative index finger length as a sex-influenced trait in man. American Journal of Human Genetics, 4, 72-89.

Pipitone, R. N., \& Gallup, G. G., Jr. (in press). Women's voice attractiveness varies across the menstrual cycle. Evolution and Human Behavior.

Rhodes, G., Simmons, L. W., \& Peters, M. (2005). Attractiveness and sexual behavior: Does attractiveness enhance mating success? Evolution and Human Behavior, 26, 186-201.

Roberts, S. C., Little, A. C., Gosling, L. M., Perret, D. I., Carter, V., Jones, B. C., et al.(2005). MHCherterozygosity and human facial attractiveness. Evolution and Human Behavior, 26, 213-216.

Roney, J. R., \& Maestripieri, D. (2004). Relative digit lengths predict men's behavior and attractiveness during social interactions with women. $\mathrm{Hu}$ man Nature, 15, 271-282.

Rubenstein, A. J., Langlois, J. H., \& Kalakanis, L. E. (1999). Infant preferences for attractive faces: A cognitive explanation. Developmental Psychology, 35, 848-855.

Shackelford, T. K., \& Larsen, R. J. (1999). Facial attractiveness and physical health. Evolution and Human Behavior, 20, 71-76.

Sheldon, W. H. (1954). Atlas of men. New York: Harper.

Singh, D. (1993). Adaptive significance of female attractiveness: Role of waist-to-hip ratio. Journal of Personality and Social Psychology, 65, 293-307.

Singh, D., \& Singh, D. (2006). Role of body fat and body shape on judgement of female health and attractiveness: An evolutionary perspective. Psychological Topics, 2, 331-350.

Sluming, V. A., \& Manning, J. T. (2000). Second to fourth digit ratio in elite musicians: Evidence for musical ability as an honest signal of male fitness. Evolution and Human Behavior, 21, 1-9.

Soler, C., Nunez, M., Gutierrez, R., Nunez, J., Medina, P., Sancho, M., et al. (2003). Facial attractiveness in men provides clues to semen quality. Evolution and Human Behavior, 24, 199-207.

Sorell, W. (1968). The story of the human hand. London: Weidenfeld and Nicholson.

Stevenson, J. C., Everson, P. M., Williams, D. C., Hipskind, G., Mahoney, E. R., Mehler, M., et al. (2006). Attention-deficit hyperactivity disorder and fluctuating asymmetry in another college sample. American Journal of Human Biology, 18, 402-414.

Thoma, R. J., Yeo, R. A., Gangestad, S., Halgren, E., Davis, J., Paulson, K. M., \& Lewine, J. D. (2006). Developmental instability and the neural dynamics of the speed-intelligence relationship. NeuroImage, 32, 1456-1464.
Thornhill, R., \& Gangestad, S. W. (1994). Human fluctuating asymmetry and sexual behavior. Psychological Science, 5, 297-302.

Thornhill, R., \& Gangestad, S. W. (1999a). Facial attractiveness. Trends in Cognitive Sciences, 3, 452-460.

Thornhill, R., \& Gangestad, S. W. (1999b). The scent of symmetry: A human sex pheromone that signals fitness. Evolution and Human Behavior, 20, 175-201.

Thornhill, R., Gangestad, S. W., \& Comer, R. (1995). Human female orgasm and mate fluctuating asymmetry. Animal Behaviour, 50, 1601-1615.

Thornhill, R., \& Moller, A. P. (1997). Developmental stability, disease, and medicine. Biological Reviews, 72, 497-548.

Van Hoof, M. H., Voorhorst, F. J., Kaptein, M. B., Hirasing, R. A., Koppenaal, C., \& Schoemaker, J. (2000). Insulin, androgen, and gonadotropin concentration, body mass index, and waist-to-hip ratio in the first years after menarche in girls with regular menstrual cycle, irregular menstrual cycles, or oligomenorrhea. Journal of Clinical Endocrinology and Metabolism, 85, 1394-1400.

Vernon, P. A., Wickett, J. C., Bazana, P. G., \& Stelmack, R. M. (2000). The neuropsychology and psychophysiology of human intelligence. In R. J. Sternberg (Ed.), Handbook of human intelligence (pp. 245-264). Cambridge, UK: Cambridge University Press.

Waas, P., Waldenstrom, V., Rossner, S., \& Hellberg, D. (1997). An adroid body fat distribution in females impairs the pregnancy rate of in-vitro fertilization-embryo transfer. Human Reproduction, 12, 2057-2060.

Wade, T. J., Shanley, A., \& Imm, M. (2004). Second to fourth digit ratios and individual differences in women's self-perceived attractiveness, selfesteem, and body-esteem. Personality \& Individual Differences, 37, 799-804.

Wickett, J. C., Vernon, P. A., \& Lee, D. H. (2000). Relationships between factors of intelligence and brain volume. Personality and Individual Differences, 29, 1095-1122.

Williams, T. J., Pepitone, M. E., Christensen, B. M., Cooke, B. M., Huberman, A. D., Breedlove, N. J., et al. (2000). Finger length patterns indicate an influence of fetal androgens on human sexual orientation. Nature, 30, 455-456.

Wilson, D. G. (1983). Finger length as an index of assertiveness in women. Personality and Individual Differences, 4, 111-112.

Zaadstra, B. M., Seidell, J. C., Van Noord, P. A. H., Te Velde, E. R., Habbema, J. D. F., Vrieswijk, B., et al. (1993). Fat and female fecundity: Prospective study of body fat distribution in conception rates. British Medical Journal, 306, 484-487.

Received September 19, 2007

Revision received October 22, 2007 Accepted October 29, 2007 